\title{
Firm-specific output limits in a posted offer market: \\ Distributive and efficiency effects
}

\author{
: Praveen Kujal \\ Departamento de Economia, Universidad Carlos III de Madrid, Calle Madrid 126, Getafe 28903, \\ Madrid, Spain \\ Received March 1992, final version received August 1992
}

\section{Abstract}

In this paper we look at the effect of the removal of firm-specific binding and non-binding quotas in experimental posted offer markets. In the experiments we see that the effect of both binding and non-binding quotas is carried over to the deregulated regime. The effect of non-binding quotas, while being in effect, on the number of contracts is (statistically) significant. We also see that distribution of surplus may actually affect the convergence path of prices. That is, with binding quotas price convergence is observed from below the competitive equilibrium.

\section{Introduction}

This paper looks at the effect of firm-specific quotas in a posted offer market. The effect of firm-specific quotas (binding or non-binding), and their removal, upon market performance has not been examined in experimental markets yet.

The only other work involving quantity controls, specifically in experimental markets, has been done by Plott (1983). However, Plott did not look explicitly at the effect of firm-specific quotas, or their removal, upon market performance Plott used quantity restrictions for the standard approach to pollution. He found that prices show little or no tendency to converge to the competitive equilibrium (CE). However, Plott did not directly control the output of the firms through 
individual firm quotas. Only the output of the market as a whole was restricted. There has been other experimental work on quantity constraints (see, Kruse et al., Davis et al.), however, the constraints are not in the form of firm-specific quotas, that are subsequently lifted.

Generally speaking, firm-specific quotas are more common than market quotas. Firm-specific quotas are used in planned economies, where the center directs individual firms to meet output goals. In the USA examples of producer-specific quotas are used in the market for hops, tobacco, oranges, lemons, grapefruit, and raisins. A new generation of pollution permits will also be firm-specific (although, the pollution permits can be traded between firms) ${ }^{1}$. We thus see that firm-specific quotas are a prevalent mode of regulatory control. Examples of market quotas (Plott, 1983) are not as common. This makes the experimental analysis of firm-specific quantity restrictions, and their removal, interesting.

In this paper we will look at the effect of individual firm quotas, and their removal, upon a posted offer institution ${ }^{2}$. In the posted offer exchange mechanism sellers post prices (offers to sell) at the start of each period. Seller prices are ranked in ascending order, and the buyers are then randomly selected. A buyer may purchase as many units as they want as long as the purchase price is less than (or equal to) their marginal valuation. After all the buyers have finished purchasing, the next period starts with the seller posting the prices. The posted offer institution is examined because it is representative of several common form of exchange, especially in many retail markets.

This study seeks to look at the effect of quotas upon:

(i) Price levels and variability. The average price level of a contract period. The price variability during that period is studied. The impact of the removal of quotas on price, and price variation, is studied. With binding quotas, economic theory predicts that the removal of quotas will cause the price to converge to the competitive equilibrium. That is, if the market price (with quotas) is above (at) the $\mathrm{CE}$, then the removal of quotas will result in the price converging to the $\mathrm{CE}$.

(ii) Market efficiency. How does the imposition of quotas affect market efficiency? That is, do firm-specific quantity controls significantly affect surplus realization in posted-offer markets.

(iii) Output (total contracts) levels. Do quotas result in an output different than what is given (by the quotas)? The impact of the removal of quotas (binding or non-binding) on market output is also of interest.

In the next section we present an experimental design developed to study these questions.

\footnotetext{
${ }^{1}$ See Franciosi et al., 1990.

${ }^{2}$ For detailed instructions see Ketcham et al., 1984.
}

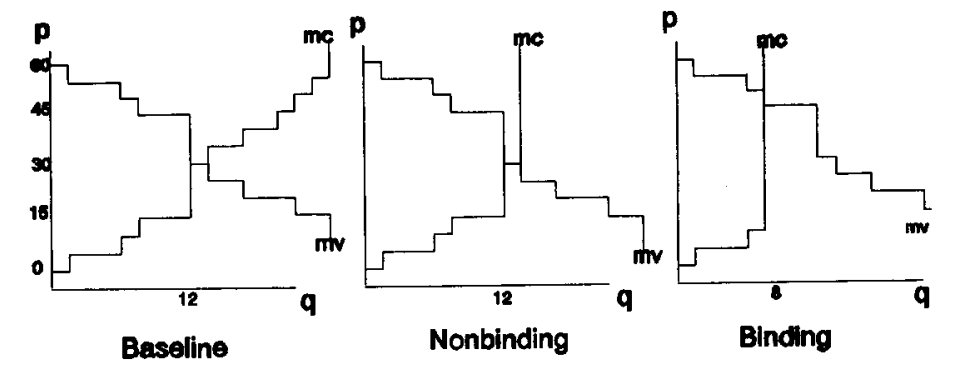

Fig. 1. Marginal cost and marginal valuations

\section{Experimental design}

$:$

The experiments used the Plato posted offer exchange mechanism. There are three different experimental designs, (i) the baseline (with no quantity restrictions), (ii) non-binding quotas (the sum of seller capacities equals the competitive outcome for the baseline; thus, the competitive price, and quantity, outcome for the baseline and the non-binding quota is the same) and (iii) binding quotas (the sum of the seller capacities is less than the competitive outcome for the baseline). In the second and third categories of experiments the quotas are removed midway ('quotas/no-quotas', or $\mathrm{Q} / \mathrm{N}$ experiments).

The impact of quotas (binding or non-binding) on prices is studied using grouped data. Paired $t$ tests are used to compare average price, price deviation (from the CE), and contract levels in the experiments. Hopefully, more insight will be gained on the impact of the removal of quotas on the institutional dynamics from the $\mathrm{Q} / \mathrm{N}$ experiments ${ }^{3}$.

As the focus of this paper is to look at seller (producer) behavior with quantity restrictions and no countervailing power (of buyers) the buyers are simulated. The buyers are perfect revealers and accept zero 'profit'. That is, buyers are willing to trade units at a price equal to their redemption values.

(i) Baseline (BSL) experiments (Fig. 1). The baseline design is characterized by four sellers capable of selling five units each and four buyers capable of buying five units each. The surplus is distributed symmetrically among the buyers and the sellers. At the CE $12-13^{4}$ units can be traded (for the resale and cost values see Table 1). Note, that units are expressed as deviations from the low cost unit.

\footnotetext{
${ }^{3}$ To control for the length of the paper the statistical results are not tabulated. The interested reader may write to the author for the longer version of the paper.

${ }^{4}$ From now on we use $\mathrm{CE}$ as being at 12 units, as the thirteenth is never traded at zero profits by sellers. We thus use the lower bound of 12 as the competitive equlibria.
} 
Table 1.

Marginal cost and marginal valuation

\begin{tabular}{llllll}
\hline & Unit-1 & Unit-2 & Unit-3 & Unit-4 & Unit-5 \\
\hline Buyer 1 & 5.60 & 5.55 & 5.45 & 5.30 & 5.20 \\
Buyer 2 & 5.55 & 5.50 & 5.45 & 5.25 & 5.15 \\
Buyer 3 & 5.55 & 5.50 & 5.45 & 5.25 & 5.15 \\
Buyer 4 & 5.60 & 5.55 & 5.45 & 5.30 & 5.20 \\
Seller 1 & 5.00 & 5.05 & 5.15 & 5.30 & 5.40 \\
Seller 2 & 5.05 & 5.10 & 5.15 & 5.35 & 5.45 \\
Seller 3 & 5.00 & 5.05 & 5.15 & 5.35 & 5.55 \\
Seller 4 & 5.05 & 5.10 & 5.15 & 5.40 & 5.50 \\
\hline
\end{tabular}

(ii) Quotas at the CE (non-binding quotas (NBQ)) (Fig. 1). In this design the sum of the sellers' capacities equals thirteen. This leaves the competitive price and quantity outcome unchanged from the baseline experiments.

(iii) Quotas below the CE (binding quotas (BQ)) (Fig. 1). Here the sum of the sellers' capacities equals eight. The competitive outcome is in a 5 cent range, from 15-20 cents above the CE in the NBQ/BSL design. In the case of binding quotas the surplus distribution is skewed in favor of the sellers.

The subjects receive a special announcement that during each trading period quantity controls will be in effect when appropriate. If any seller attempts to violate the quota restriction, that is, sell more units than their (maximum) production quota, this results in the rejection of the sellers offer until the output constraint (quota) is satisfied. This design is similar to that used by Coursey and Smith (1983), except that firm quotas are used instead of price controls. Subjects are also told that their capacity is determined by a central authority. This announcement is made to all the subjects. They are also given individual announcements that state their capacities. The announcement at the start of the experiment reads: "Your capacity is determined by a central authority. Your capacity is .... Please make sure that the number on the screen coincides with the capacity stated."

One period prior to the removal of the quotas, an announcement is again made in regards to the change in capacity. Subjects are told individually what their "new" capacities are. Note, that everyone knows that the individual capacities have been changed, however, individual capacity changes are private information. The announcement reads as follows: "The central authority has now decided to change your capacities. You now have a capacity of FIVE units. Please make sure that the monitor screen shows the correct amount."

The purpose behind the announcements is to emulate an environment where capacities are announced by a central authority. That is, authorities announce their intention to increase (or, decrease) the quota limits set upon firms.

Each trading period starts with a seller posting the price, and the total number of units she is willing to sell at that price. Once all the sellers have made their final offers, they are notified about the other sellers' offer prices. The buyers are then randomly queued to initiate the buyer procedure. If the units available from a particular seller have been exhausted, they are given the message 'out of stock'. After all the buyers have completed their purchasing the trading period ends. Each experiment consists of twenty trading periods. The trading periods are split into groups of ten each. For the $\mathrm{Q} / \mathrm{N}$ experiments quantity controls are in effect for the first ten periods, and removed for the remaining ten periods.

The rationale behind the quotas at the $\mathrm{CE}$ is that we want to see how much distortion 'mere' quotas can cause. That is, with quotas at the CE, do we get the same outcome as the theoretical competitive (price and quantity) outcome (with and without quotas)? We can thus test whether quotas alone, or their removal, can cause the market outcome to change.

With non-binding quotas each individual firm can sell at most three units (the same as at the CE for the baseline). However, seller 1 has an additional unit at the CE. (The competitive outcơme of 12 (and not 13) is realized as we do not give commissions for the units traded.) With the binding quotas each individual firm can sell at most two units.

\section{Experimental results}

We report results from five experiments each for the baseline, binding quotas, and non-binding quotas.

In our experiments we get two interesting results from non-binding and binding quota experiments. In the non-binding quota experiments the number of contracts remains well below the competitive level of 12 (the number of contracts is also less than in the baseline experiments). After the (non-binding) quotas are removed, output in the subsequent periods remains depressed and slowly starts to converge towards the competitive outcome (similar results are obtained for binding-quota experiments). This result duplicates similar results obtained in price control experiments (see, Coursey-Smith, Isacc-Plott, and Smith-Williams).

In the binding quota experiments, the average price converges from below the CE when the quotas are in effect. This result contradicts the well known artifact that average price in the posted offer experiments converges from above ${ }^{5}$. (The upper support of the CE price with binding quotas is $\$ 5.50$, and the lower support is $\$ 5.45$ ).

Paired $t$-tests are used to test for the impact of quotas upon contracts and price. Paired $t$-tests are also used to compare deviations from the CE for the BQ-NBQ, and BQ-BSL, pairings. That is, the number of contracts in each experiment is paired (pair-wise) against the contracts in the non-binding quota and the baseline experiments.

${ }^{5}$ For a discussion on asymmetric surplus distribution and the price convergence path see Kujal, P., 1992. 
The paired $t$-tests on contracts show that non-binding quotas tend to depress the number of contracts significantly. For the NBQ-BSL pair 15 (of 25) pairs are significantly different at the $95 \%$ confidence level (cl), and 21 at the $90 \% \mathrm{cl}$. We thus see that non-binding quotas have a marked impact on the number of units contracted.

Paired $t$-tests on posted and contracted prices are also done. For contracted prices we see that for the NBQ-BSL 2 pairs are significantly different at the 95\% $\mathrm{cl}$, and 5 at the $90 \% \mathrm{cl}$. For the BQ-NBQ pair 8 are significantly different at the $95 \% \mathrm{cl}$, and 12 at the $90 \% \mathrm{cl}$. Similarly, for the BSL-BQ pair 5 are different at the $95 \% \mathrm{cl}$, and 6 at the $90 \% \mathrm{cl}$.

For the posted prices we see that the results are slightly different. That is, the BSL-BQ comparison has 5 significantly different at the $5 \% \mathrm{cl}$, and 6 at the $90 \%$ cl. For the BSL-NBQ pairing we see that 2 are significantly different at the $95 \%$ $\mathrm{cl}$, and 5 at the $90 \% \mathrm{cl}$. Similarly, the BQ-NBQ comparison shows that 8 are significantly different at $95 \%$ and 12 at $90 \%$ cl.

We thus present conclusive evidence in favor of the impact of quotas on the number of units contracted. However, the impact on prices is mixed for individual experiments, though conclusive for the estimates run on pooled data (cross section time series). Also, price adjustment is significantly affected by quotas.

Below, we discuss the outcomes for each experimental design.

\subsection{No quantity controls (baseline)}

In these experiments price converges from above the $\mathrm{CE}$. The average price decreases as the experiment progresses, however, price convergence is slow (Figs $2 \mathrm{a}$ and $2 \mathrm{~b}$ ). In all the (five) experiments contracts converge to the CE outcome (12) between the seventh period and the twelfth period (Fig. 3). In the experiments that converge late, contracts converge within one unit of the $C E$ around period eight or nine. The average efficiency levels in the five experiments converge to high 80 th percentile by the 12th period (Fig. 4). No experiments reached efficiency levels in the high nineties ${ }^{6}$.

Slow price convergence (to the $\mathrm{CE}$ ) can be explained by the fact that at the $\mathrm{CE}$ the demand and supply steps (supports) are separated by 30 cents. Thus, the CE is not the Nash equilibria. For example, let three sellers post prices at the competitive equilibrium (\$5.30). This implies that each one of them can sell three units at the CE. Let the sellers be sellers $2-4$, this implies that seller 1 can make an offer of $\$ 5.35$ (sell all his units) and make a larger profit. However, any price greater than $\$ 5.35$ will allow sellers 2 and 3 to sell their extra-marginal units. Thus, CE is not the pure strategy Nash equilibria. If all sellers price in this fashion, we will get

\footnotetext{
${ }^{6}$ All the experiments exhibit relatively low efficiency levels compared to the posted offer price control experiments in Coursey and Smith (1983).
}

price cycles between the lower and upper bounds of the MSN. As a result we may not get convergence to the $\mathrm{CE}$. This may explain the slow (or no) convergence to the CE.

Now, looking at efficiency levels we see that the average efficiency levels are relatively low. Efficiency levels of $100 \%$ are never reached in any of the experiments (almost all experiments reach efficiency levels in the high eighties) This may also have to do with experimental design where one gets Edgeworth cycles. That is, we may observe price cycles whereby sellers may price themselves out of the market, resulting in subsequently lower prices. Price cycles as these may result in contracts less than the CE (12 units), and hence lower efficiencies.

\section{Baseline vs. Non-Binding Quota}

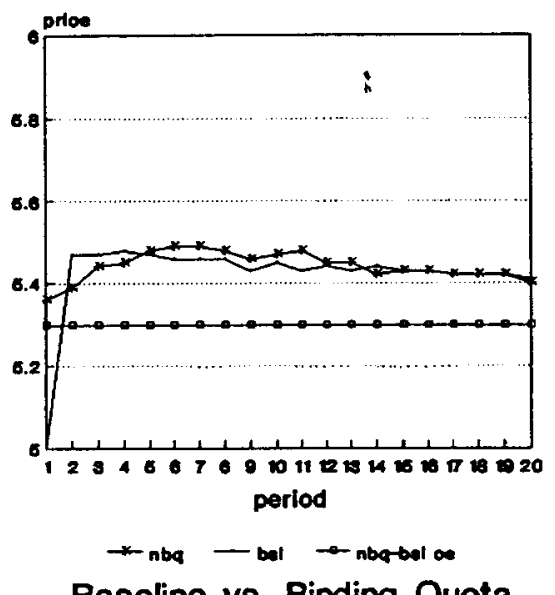

Baseline vs. Binding Quota
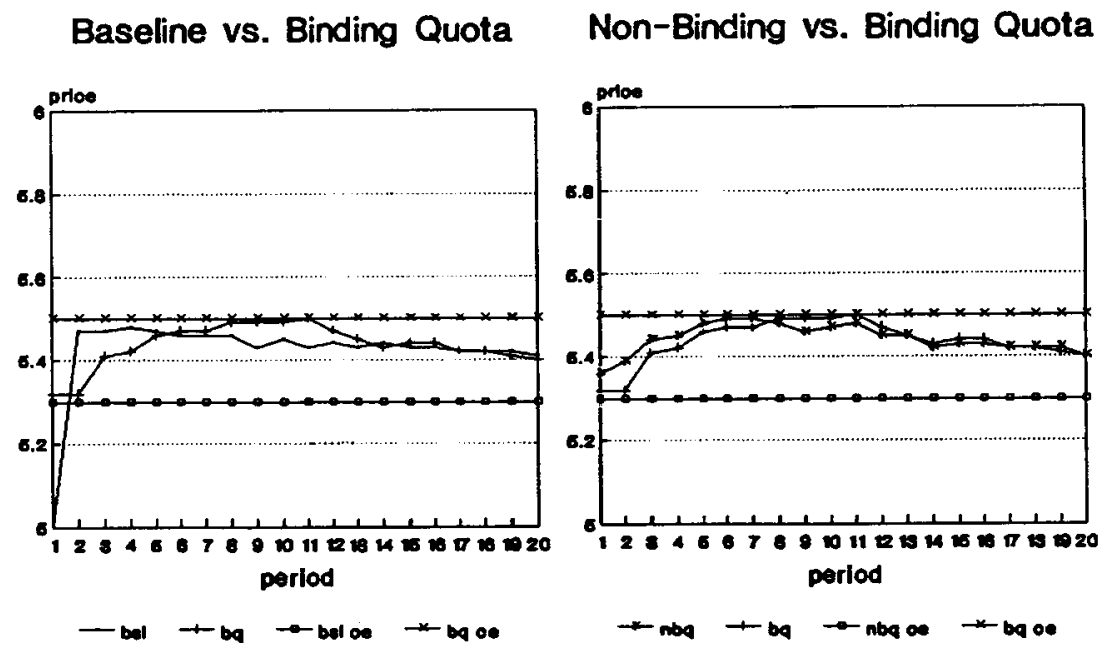

Fig. 2a. Contracted prices 


\section{Baseline vs. Non-Binding Quotas}

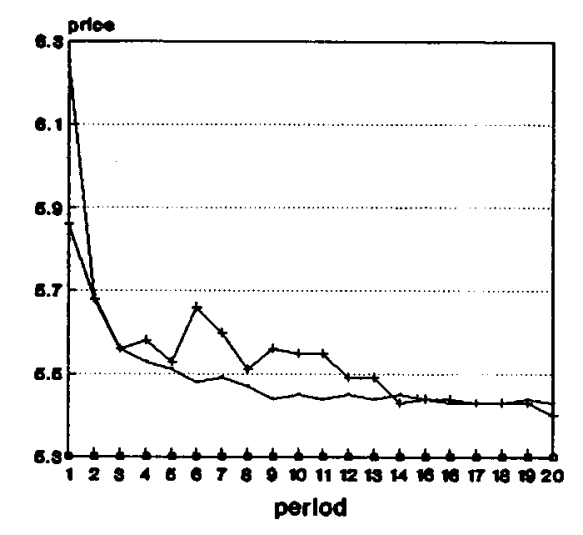

- bas + nba $\rightarrow$ bal-nba oe

Non-Binding vs. Binding Quotas

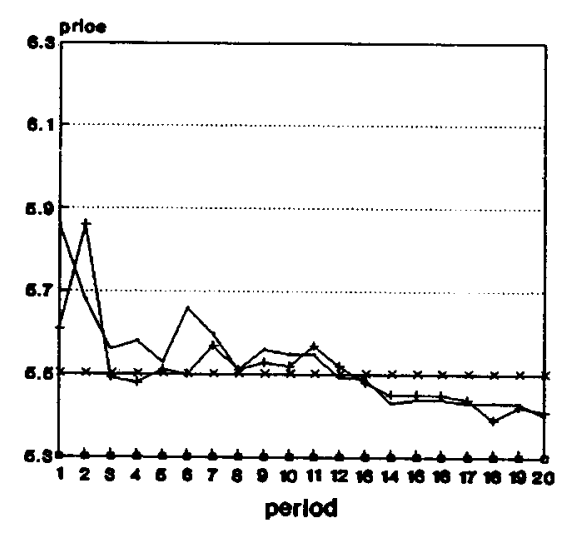

perlod

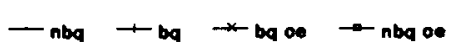

Fig. 2b. Posted prices

\section{Baseline vs Binding Quotas}

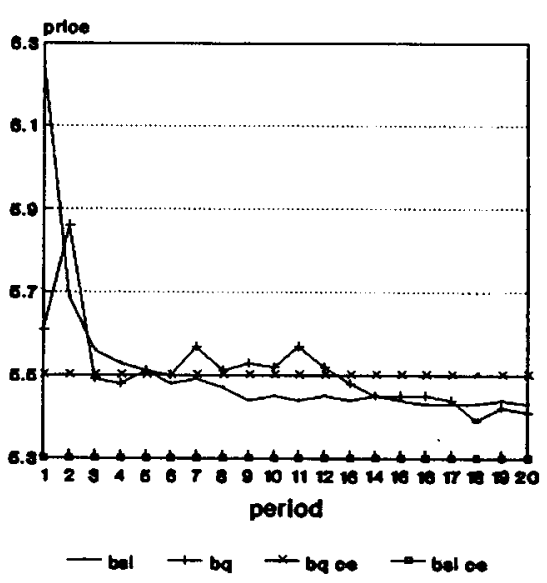

\subsection{Non-binding quotas $(N B Q)$}

Five experiments are run with non-binding quotas. In all the experiments no noticeable change in the average contracted price is observed after the (non-binding) controls are removed. As far as price convergence is concerned (see Figs. 2a and $2 \mathrm{~b}$ ), one can see that the average price decreases across periods, however, it does not converge to the $\mathrm{CE}$.

It is quite evident that non-binding quotas affect the units contracted. In the five experiments quantity sold is substantially less than the CE quantity of 12 (see Fig.

\section{Baseline vs Non-Binding Quotas}

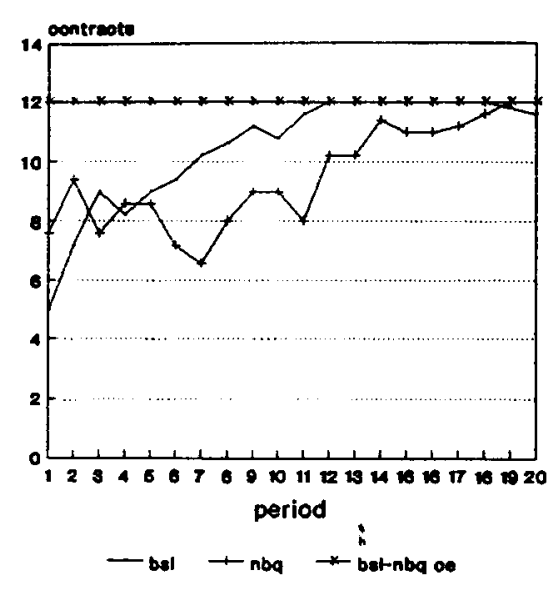

Baseline vs Binding Quota

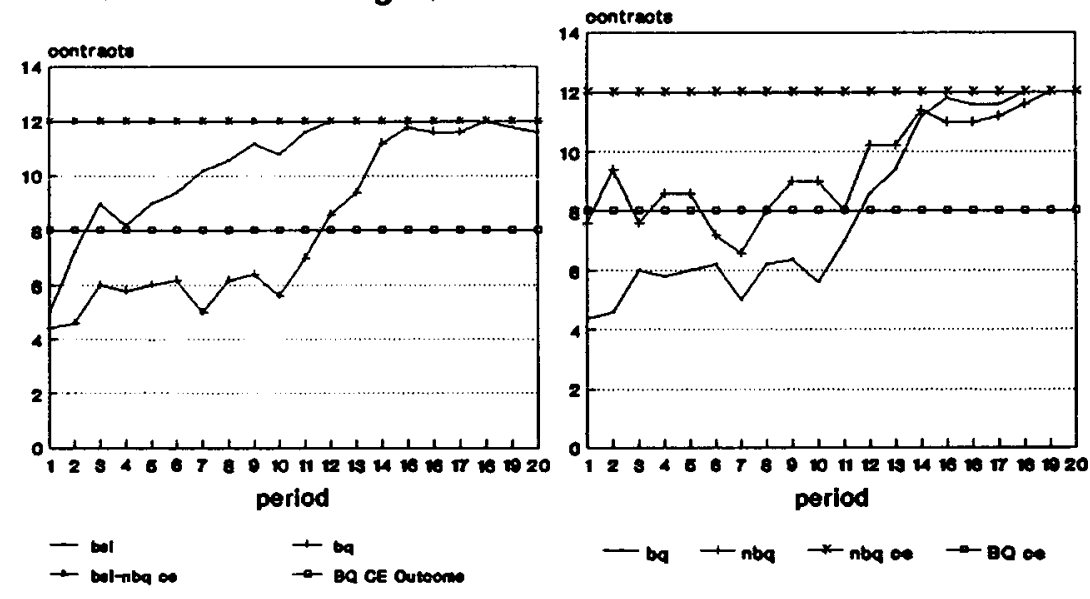

Fig. 3. Average contracts

3). Comparing this with the baseline we see that units contracted are less than under the baseline and remain so even after quotas are removed (Fig. 3).

We thus see that non-binding controls tend to depress the units contracted, and also affect the contracts in the subsequent periods. It is also evident that the effect of non-binding controls is carried over to the regime without controls.

Now, looking at average (contracted) prices we see that the average price in the NBQ design (for all five experiments) is slightly above the average price in the baseline experiment from period five to fourteen (see Fig. 2a). Interestingly, if we look at the posted prices (Fig. 2b) we see that when non-binding quotas are in 


\section{Total Realized Surplus}

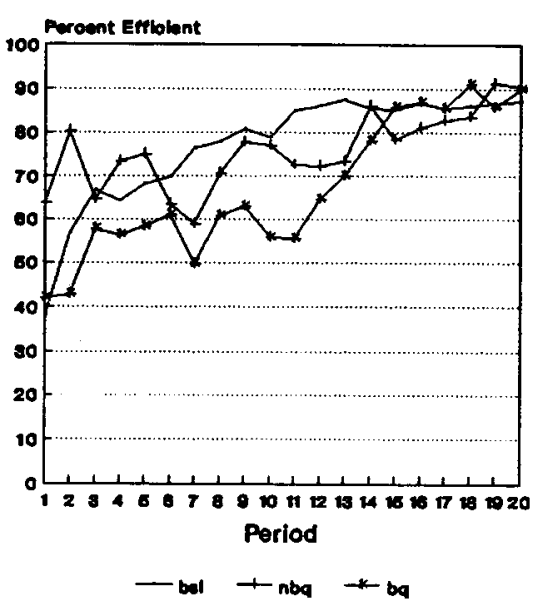

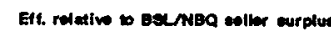

Buyers-Realized Surplus

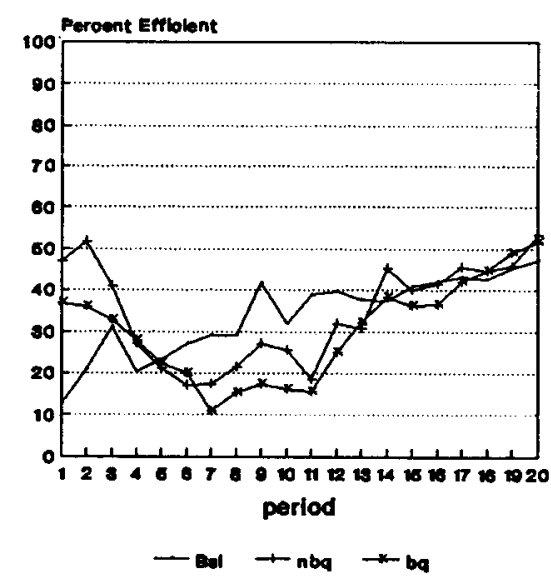

Fig. 4. Average realized surplus

effect, average prices are slightly above the baseline prices, and show higher variation (relative to the $\mathrm{CE}$ ) compared to the (average) prices in the baseline experiments. Thus, posted prices seem to have a larger variation while non-binding controls are in effect ${ }^{7}$.

\section{Sellers-Realized Surplus}

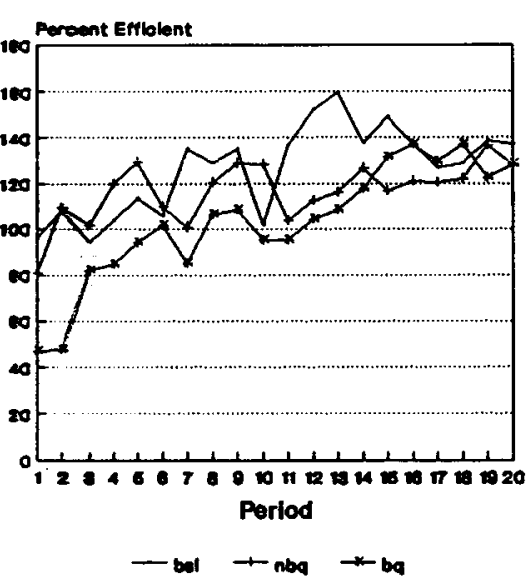

${ }^{7}$ See Kujal, ibid.

From the data available so far we see that non-binding quotas cause units contracted to be below the CE, and contracts remain depressed even after the removal of non-binding controls. Both posted and contracted prices seem to be slightly higher than prices in the baseline experiments. Also, posted prices exhibit higher variation when non-binding quotas are in effect (compared to the baseline experiments).

The impact of non-binding quotas on seller surplus share is best studied by comparing it with the baseline. Concerning the sellers' share of the total surplus, we see that the realization in the first period is at $80.77 \%$, eventually climbing to $127.46 \%$ (Fig. 4). This realization is $10 \%$ lower than the baseline. Paired $t$-tests suggest that the seller realization of surplus under the baseline design is significantly different than the (seller) realization of surplus in the non-binding quota design.

3.3. Binding quotas $(B Q)$ :

Five experiments are run with binding controls. With binding controls all sellers can sell at most two units. After the controls are removed they can sell three units each at the CE.

An interesting result arising from these experiments is that the average contracted price converges (Fig. 2a) from below the CE (CE has a spread of five cents) while the binding quotas are in effect. (The upper and lower support of the $\mathrm{CE}$ is $\$ 5.50$ and $\$ 5.45$, respectively.) The average contract price in the first period of the (five) $\mathrm{BQ}$ experiments is lower than the average contracted price in the NBQ experiment for the first seven periods. The average contracted price is also below the first five periods of the BSL experiments. This price convergence from below the CE is unlike price convergence in other posted offer experiments ${ }^{8}$.

Comparing the average posted price we see that it starts above the $\mathrm{CE}$ for all the experiments. The average posted price in the BQ experiments is less than the posted price in the BSL experiments for the three (out) of the first four periods, and for the first nine periods against the NBQ experiments. We thus see that the average price, posted or contracted, is depressed in the initial periods of the $B Q$ treatment.

One can argue that convergence from below may be observed whenever one has distribution of surplus favoring the sellers. That is, in the limit, if the consumer surplus is zero (and the resale values of the buyers is the same as CE) one will observe price convergence from below the $\mathrm{CE}$. A question that arises out of this is, "What distribution of asymmetric surplus will switch the convergence from above CE to below it". To answer this question empirically, experiments can be run to see when this happens.

Also, the effect of quotas upon the post-quota regime is evident. That is,

${ }^{8}$ See Kujal, ibid. 
contracts in periods $11-14$ (Fig. 3) tend to remain below the CE. The impact of quotas (binding or non-binding) into the post-quota regime is also observed in the NBQ experiments.

Comparing the total realization, we see that (note, all BQ efficiencies are relative to the BSL design) binding quota design is the least efficient of all at $66.98 \%$. The other two designs show average total realization at $76.97 \%$ and $75.86 \%$, for the BSL and NBQ design respectively. Also, $t$-tests confirm that the pairs, BSL-BQ and BQ-NBQ, are significantly different at the $1 \% \mathrm{cl}$

We thus see that non-binding quotas significantly affect the number of contracts. The impact on prices using $t$-tests is not significant, however, regression run on the aggregate data indicate that non-binding quotas affect prices and price adjustment significantly.

\section{Conclusion}

Two interesting results arise from the experiments run above. First, as has been observed in the price control experiments, non-binding price controls tend to substantially affect institutional performance. One sees that the institutional effects of non-binding quotas are carried over to periods without the quantity constraints. Thus, past regulatory controls affect institutional performance in the future (as has also been observed in the price control experiments).

Second, with binding quotas (average) price convergence is observed from below the $\mathrm{CE}$. This is unlike the results observed in other posted offer experiments done and is contrary to the claim by Davis and Williams (1986) that the convergence path of prices is not affected by surplus distribution.

We also see no jump (or overshoot of the $\mathrm{CE}$ ) in price after the quotas, binding or non-binding, are removed. This overshooting, prevalent in all the price control experiments (both in the posted offer and the double oral auctions), does not seem to carry over to the quota experiments. For the aggregate model (cross section time series) estimates we observe that prices seem to be significantly affected by the non-binding quotas. This is not affirmed by the individual experiment estimates.

As far as distribution of surplus is concerned, surprisingly, with binding quotas sellers have low efficiency levels (on the average).

Looking at the impact of quotas on prices, price deviation, and contracts, in the aggregate, we can say that quotas, binding or non-binding, affect all these variables. Individual responses vary, and some individual sellers behavior is not consistent with the aggregate results. However, what is evident is that market controls, binding or non-binding, affect market performance.

\section{Acknowledgement}

I would like to thank Mark Isaac, Ron Oaxaca, Doc Ghose, Jim Cox, Tim Cason, and participants at the Economic Science Association meetings (1991) for helpful comments. The experiments were funded by the Economic Science Laboratory.

\section{References}

Coursey, Don L. and Vernon L. Smith, 1983, Price Controls in a Posted Offer Market, AER, Vol. 73, No. 1.

Davis, Douglas D. and Arlington A. Williams, 1986, Rent Asymmetries in Posted Offer Markets, Journal of Economic Behavior and Organization 7, 303-316.

Franciosi, Robert, Mark Isaac, David Pingry and Stanley Reynolds, 1990, Marketable Acid Rain Emission Permits: An Investigation of Revenue Neutral Auctions, Journal of Environmental
Emios, Robert, Mark Isaac, David Pingry and Stanley Reynolds, 1990, Marketable Acid Rain Emission Permits: An Investigation of Reven
Economics and Management 24, 1-24, 1993.

Holt, Charles A., 1985, The Exercise of Market Power in Laboratory Experiments, Journal of Law and Economics 75, 314-325.

Holt, Charles A. and Fernando Solis-Soberon, 1992, The Calculation of Mixed-Strategy Equilibria in Posted-Offer Markets, in: Research in Experimental Economics, Vol. 5.

Isaac, R. Mark and Charles R. Plott, 1981, Price Controls and Behavior of Auction Markets: An Experimental Examination, AER, Vol. 71, June, 449-459.

Ketcham, Jon., Vernon L. Smith and Arlington W. Williams, 1984, A Comparison of Posted Offer and Double Auction Pricing Institutions, Review of Economic Studies 167, 595-614.

Kruse, Jamie., Stephen Rassenti, Stanley S. Reynolds and Vernon L. Smith, 1987, Bertrand-Edgeworth Competition in Experimental Markets, Discussion Paper No. 87-12, Department of Economics, University of Arizona.

Kujal, Praveen, 1991, Removal of Firm Specific Output Limits and Dynamic Market Power, University of Arizona.

Kujal, Praveen, 1992, Asymmetric Surplus Distribution and the Price Convergence Path in Posted-Offer Markets: A Note, Economics Letters 39.

Plott, Charles R. and Vernon L. Smith, 1978, An Experimental Examination of Two Exchange Institutions, Review of Economic Studies 45, 133-153.

Smith, Vernon L. and Arlington W. Williams, 1981, On Non-binding Price Controls in a Competitive Market, AER, Vol. 71, June, 467-74.

Weitzman, Martin L., 1974, Price vs. Quantities, Review of Economic Studies, February, 477-91. 